\title{
Higher Dietary Cost Is Associated with Higher Diet Quality: A Cross-Sectional Study Among Northeast Central Chinese Adults
}

\author{
Junya Zhai ( $\nabla$ zhaijunya1229@126.com ) \\ Affiliated Cancer Hospital of Zhengzhou University, Henan Cancer Hospital \\ Baihui Ma \\ Affiliated Cancer Hospital of Zhengzhou University, Henan Cancer Hospital \\ Saiqi Wang \\ Affiliated Cancer Hospital of Zhengzhou University, Henan Cancer Hospital \\ Quanjun Lyu \\ The first affiliated Hospital of Zhengzhou University \\ Lijun Guo \\ Affiliated Cancer Hospital of Zhengzhou University, Henan Cancer Hospital \\ Pipasha Khatun \\ College of Public Health of Zhengzhou University \\ Rui Liang \\ The first affiliated Hospital of Zhengzhou University \\ Minghua Cong \\ National Cancer Center, Chinese Academy of Medical Sciences and Peking Union Medical College \\ Yongxia Kong \\ Affiliated Cancer Hospital of Zhengzhou University, Henan Cancer Hospital
}

\section{Research Article}

Keywords: diet quality, diet cost, association

Posted Date: February 2nd, 2022

DOI: https://doi.org/10.21203/rs.3.rs-1306384/v1

License: @) (1) This work is licensed under a Creative Commons Attribution 4.0 International License. Read Full License 


\section{Abstract}

Objectives: Food price is a determining factor in food choices. However, its relationship with diet quality is unclear in Chinese adults. This study aimed to examine daily energy-adjusted dietary cost (Chinese Yuan, CNY/2000kcal) concerning diet quality in northeast central Chinese adults.

Methods: The food consumed by 680 Chinese adults from Henan province during the year 2020 was recorded by 24-h dietary recalls. Three dietary quality indices, namely the nutrient-rich foods (NRF) index, the mean adequacy ratio (MAR), and the energy density (ED), were adopted. Daily energy-adjusted diet cost was calculated by dividing the estimated daily diet costs (CNY/day) by the energy intake per day (kcal/day) and multiplying 2000.

Results: Subjects who closely adhered to the NRF9.2, MAR, and ED paid daily $¥ 8.92, ¥ 13.17$, and $¥ 14.34$ more for food consumption, respectively, than those who weakly adhered to these dietary patterns. Furthermore, adjusted linear regression analysis revealed that an increase in $¥ 1$ of the energy-adjusted diet cost per day was associated with a change of 0.494 units $(P<0.001), 0.003$ units $(P<0.001)$, and -0.018 units $(P<0.001)$ in the NRF9.2, MAR, and ED, respectively.

Conclusion: Higher energy-adjusted diet costs were associated with higher-quality diets. This might be of importance for public health policies in an effort to develop strategies to promote healthy diets by regulating food and diet costs.

\section{Introduction}

Unfavorable diet quality is a big public health issue inmany countries.A sub-optimal diet is responsible for more deaths than any other risks globally, highlighting the urgent need for improving the human diet across nations ${ }^{[1]}$.A large number of studies have confirmed that diet quality is an important contributing factor to the aetiology of non-communicable diseases (NCDs) ${ }^{[1]}$, which was associated with a significant reduction in the risk of all-cause mortality,cardiovascular disease, cancer, type 2 diabetes, neurodegenerative disease ${ }^{[2]}$ and even mental illness ${ }^{[3]}$. The World Health Organization's (WHO) global action plan for the prevention and control ofNCDs 2013-2020 encourages member states to take action to increase the availability,affordability, and acceptability of healthier food products for improving diet quality ${ }^{[4]}$.

Research has shown that food choices have influenced diet quality bymany factors. These include prices and income, time constraints, environmental factors, community characteristics,family structure, psychological factors, and nutritional information ${ }^{[5]}$. While increased monetary cost is often cited as a major barrier to improved diet quality ${ }^{[6]}$. Several studies that examined the relationship between diet quality and diet cost have been carried out by publichealth and nutrition experts. For example, monetary diet cost is positively associated with diet quality in Americans ${ }^{[7]}$, Malaysian ${ }^{[8]}$, and Spanish ${ }^{[9]}$. Meanwhile, higher diet quality was alsoassociated with higher diet costs ${ }^{[10,11]}$. Subjects who closely adhered to higher diet quality paid more for food consumptionthan those who weaklyadhered to these dietary patterns ${ }^{[9]}$. However, there is no consensus on thisissue. At least two intervention studies in the USA purportto show that higher-quality diets are not more expensivethan lower-quality diets and may even cost less ${ }^{[12,13]}$.

While the associations linking dietary cost and diet quality remain mostly unexplored in Chinese, except forone study discussed among school-aged children ${ }^{[14]}$.Generally, Chinese dietary patterns and diet-related behaviors have undergone a significant transition in the past few decades, trending towards diversification and modernization ${ }^{[15]}$. Therefore, there is a need for improvement in diet quality for the Chinese adults. Although several measures are being taken by the ministry of health, China, thereis a need to investigate the daily dietary costand its relationshipto diet quality, which may assist health professionals todevelop targeted strategies and tailored advice aimed atimproving overall diet quality.

\section{Subjects And Methods}

\subsection{Study design and population}


Participants for the study were from the cross-sectional study, which aimed to collect information on the diet, personal data of adults aged 25-75 years in 3 communities in Zhengzhou city, China 2020. 680 individuals were analyzed in this study after excluding individuals with incomplete data and implausible energy intake ${ }^{[16]}$. The study was approved by the Institutional Review Board. Written informed consent was obtained from all subjects.

\subsection{Dietary and covariant assessment}

Personal data had collected by a structured questionnaire where dietary assessment had recorded through two nonconsecutive 24-h dietary recalls. Personal data had included gender, age, marriage, personal income, family numbers, family income, education, and job. To help the respondents answer accurately, dietary intakes had assessed by 24-h diet recalls were investigated face to face with the aid of food models. The average daily intakes of various foods and nutrients had analyzed by nutrition calculator (NCCW software), which based on the China Food Composition Tables ${ }^{[17]}$.

\subsection{Evaluation of Nutrient-rich food index scores}

NRF9.2 index, based on 9 beneficial nutrients and 2 nutrients to limit, using the algorithm based on sums and $100 \mathrm{kcal}$ was the bestpredicted model for Chinese adults, and thus it was selected in this study. The daily reference intakes of nutrients had based on the recommended nutrient intake (RNI) or adequate intake ( $\mathrm{Al}$ ) of adults except for saturated fat, which had based on acceptable macronutrient distribution ranges ${ }^{[18]}$. All foods consumed by each subject had scored using the NRF9.3 algorithms followed by the NRF9.3 score per $100 \mathrm{kcal}^{[19]}$.

\subsection{Assessment of nutrient adequacy}

Nutrient adequacy was measured by computing the mean adequacy ratio (MAR) ${ }^{[20]}$. To compute MAR and nutrient adequacy ratio (NAR) first of all, calculate the selected 10 nutrients, include energy, protein, vitamin $A$, vitamin $C, C a, F e, P$, vitamin $B_{1}$, vitamin $B_{2}$, and niacin. NAR was calculated based on Chinese Dietary Reference Intakes (DRIs) ${ }^{[18]}$. MAR was calculated as described by Madden et al[20].

\section{$\mathrm{NAR}=\frac{\text { Actual nutrient intake of a nutrient (per day) }}{\text { Chinese daily reference intakes of the nutrient }}$}

\section{MAR $=\frac{\sum \text { NAR }(\text { each truncated at } 1)}{\text { Number of nutrients }}$}

\subsection{Calculation of energy density}

Energy density (ED, $\mathrm{kcal} / \mathrm{g}$ ) refers to the amount of energy in a given weight food. Energy density values vary widely, depending on whether water and non-calorie-containing and calorie-containing beverages have been included from the analysis ${ }^{[21,22]}$. Based on past research ${ }^{[21]}$, the present calculations on foods only, because the energy density of the solid part of the diet is reported a better indicator of dietary quality than energy density based on food and energy-yielding beverages. Diet porridge was divided according to its ingredients and converted into purchasable forms. For example, a bowl of rice porridge was broken into two separate ingredients: rice and water, and water also were excluded when calculating ED.

\subsection{Daily diet costs}

Monetary costs of diets obtained from the 24-h dietary recalls (CNY/day) had calculated by multiplying the amount of food consumed (100 g/day) by the estimated price of each food (CNY/100 g) and summing the products. The procedure for estimating costs was based on the assumption that all foods were purchased and then prepared and consumed at home. Ultimately, 428 food and beverage items were analyzed. The price of each food was obtained first from the Zhengzhou 
Municipal Development and Reform Commission website ${ }^{[23]}$ (59 of 428 items; $13.8 \%$ ). For food items whose prices are not published on the official website (356 of 428 items; $83.2 \%$ ), prices were taken from four supermarkets and three farmers' markets, and the average prices were used in the analysis. Prices of fast food items (13 of 428 items; $3.0 \%$ ) were taken from fast-food restaurants (McDonald's, KFC, DICOS in Zhengzhou city). Discounted prices were not used to determine the food costs.

The calculation included correction for preparation and waste using the China Food Composition database ${ }^{[17]}$. Prices were expressed in Chinese Yuan (CNY, $¥)$ per $100 \mathrm{~g}$. Since monetary diet cost had observed to be strongly associated with energy intake ( $y=0.58)$, diet cost per $2000 \mathrm{kcal}$ of energy intake per day (hereinafter, energy-adjusted diet cost) had calculated by dividing the daily diet cost (CNY/day) by the energy intake per day (kcal/ day) and multiplying 2000.

\subsection{Quality control}

Quality control had carried out during the whole process. Firstly, the questionnaire used in the investigation was revised after a pilot study and expert discussion. Secondly, all investigators must undergo training before the interview. Last but not the least, all data were inputted by two persons, and logical error detection and review were carried out.

\subsection{Statistical analysis}

All statistical analyses were performed using SAS statistical software(versions 9.3,2011). Analyses used t-tests or analysis of variance for normally distributed continuousvariables, Wilcoxon rank sum tests for non-normally distributed continuous variables, and chi-square tests for categorical variables. All calculated $P$-values were two-tailed and were considered statistically significant at $<0.05$ for a single variable. Data for daily diet cost and daily energy-adjusted diet cost had compared according to socio-demographic characteristics. We calculated the crude means of food group intake and nutrients intake within each quartile of daily energy-adjusted diet cost. Multivariate linear models were used to provide covariate-adjusted means of daily energy-adjusted diet costs among strata of the diet quality index (NRF9.2, MAR, ED). Meanwhile, multivariate linear models were also used to provide covariate-adjusted means of the diet quality index among strata of daily energyadjusted diet costs. Covariates included age (years), gender (male or female), family income level ( $¥ 2000 /$ month/person, $¥ 2000-¥ 5000, \geq ¥ 5000$ ), and food intake (kcal).

\section{Results}

3.1 Sample characteristics. We analyzed data from a sample of 680 northeast central Chinese adults. Estimates of mean daily diet costs and daily energy-adjusted diet costs are provided for demographic and socio-economic groups in Table 1 . The mean of daily diet costs and daily energy-adjusted diet costs was $¥ 14.05 /$ day and $¥ 19.14 / 2000$ kcal, respectively. Daily diet cost was slightly higher for men ( $¥ 14.51 /$ day) than women ( $¥ 13.32 /$ day). However, the difference reversed after adjusting for energy. For each $2,000 \mathrm{kcal}$ of dietary energy, men spent $¥ 18.43$ compared to $¥ 20.30$ spent by women. The daily and energyadjusted diet cost of higher family income groups was greater than that of the lowest ones (Table 1).

3.2 Means of food group intake and nutrients within each quartile of daily energy-adjusted diet cost. Since monetary diet cost was observed to be strongly associated with energy intake $(Y=0.58)$, daily energy-adjusted diet cost was adopted in the following analysis. At the food level, participants in the higher quartiles of daily energy-adjusted diet cost had higher mean values of diet cost for fruit, milk and milk products, beans, nuts, meat and poultry, fish and lean meat, and other food groups, and had lower mean values of diet cost for the grain foods (Table 2). At the nutrient level, higher daily energy-adjusted diet costs wereassociated with greater intakes of protein, vitamin $B_{2}$, niacin, vitamin $A$, vitamin $C$, vitamin $E$, potassium, calcium, zinc, and MAR,and lower intakes of energy, fat, carbohydrate (Table 3).

3.3 Multiple linear regression for the association of daily energy-adjusted diet costs with diet quality.A significant, positive association was observed in themultivariate models for NRF9.2 ( $\beta=0.284$, Pfor-trend $<0.0001)$, MAR $(\beta=44.77$, Pfortrend $<0.0001$ ), and ED ( $\beta=-11.51$, Pfor-trend $<0.0001$ )(Table 4).Subjects who closely adhered to the NRF9.2, MAR, and ED daily 
paid $¥ 8.92, ¥ 13.17$, and $¥ 14.34$ per 2000 kcal more for food consumption, respectively, than those who weaklyadhered to these dietary patterns. With each 1-point increasein NRF9.2, MAR, and ED, the diet cost increased $¥ 0.29, ¥ 44.77,-¥ 11.51$ per 2000 kcal.

3.4 Multiple linear regression for the association of diet quality with daily energy-adjusted diet costs.Adjusted linear regression analysis revealed that an increase in $¥ 1$ of the energy-adjusted diet cost per day wasassociated with a change of 0.494 units $(P<0.001), 0.003$ units $(P<0.001)$, and -0.018 units $(P<0.001)$ in the NRF9.2, MAR, and ED, respectively $($ Table 5$)$.

\section{Discussion}

This study examined diet cost and diet quality in a sample of northeast central Chinese adults. Overall, nutrient density, the mean adequacy ratio (MAR), and dietary energy density were independent predictors of the daily energy-adjusted diet cost. Whereas the more energy-dense diets cost less, the more nutrient-dense and nutritional quality diets were found to cost more. These associations were independent of each other and were not influenced by age, sex, energy intake, or family income.

Participants reported spending $¥ 14.05$ on food and non-tap water beverages during every 24-hour observationperiod, while spending $¥ 19.14$ per $2000 \mathrm{kcal}$, which were similar to the estimated mean expenditures on food at home ( $¥ 19.99 / 2000 \mathrm{kcal})$ based on retail prices on the Nantong city of China ${ }^{[24]}$, and were similar to the cost of school-aged children in Southwest China $(¥ 11.0 / 1000 \mathrm{kal})^{[14]}$. The differences between several socio-demographic characteristics and daily diet cost or daily energyadjusted diet costwere explored. As we know a major determinant of economic well-being is the level of income that a household receives. The present results confirm past observations that family income appears to be an important correlate with food expenditure patterns ${ }^{[25]}$.

This study showed that participants in the higher quartiles of daily energy-adjusted diet cost spent more on fruit, high protein foods, and other food groups, and less on the grain foods. At the nutrients level, the lower cost diets contained more energy, total fat, and carbohydrate, and contained fewer micro-nutrients such as vitamins A, and C. No matter from the point of view of food or nutrients, it is consistent with the recommendations of the Chinese Guidelines for Chinese Residents ${ }^{[26]}$, which also was similar to that of a study in the America ${ }^{[27]}$.

Subjects who closely adhered to the high-quality diets paid more for food consumption than those who weakly adhered to these dietary patterns. Meanwhile, increasing the daily energy-adjusted diet costs was associated with a positive change in diet quality. The present data confirm previous observations, based on a representative sample of the French population ${ }^{\text {[28] }}$ and the Americans ${ }^{[27]}$, that lower-cost diets are energy-dense and nutrient-poor. By contrast, higher quality diets cost more. Several studies have emphasized that the food budgets of the poor are insufficient to obtain a balanced diet ${ }^{[29]}$. Even when low-income groups develop efficient purchasing strategies ${ }^{[30]}$, the food budget may not be adequate to procure the recommended diet.

Dietary energy density is one index of the overall quality of the diet ${ }^{[31]}$. Diets high in whole grains, lean meats, fish, and fresh vegetables, and fruit have a low energy density and a high content of vitamins and minerals ${ }^{[31]}$, which are more costly per kilocalorie than are energy-dense diets rich in fats and sweets ${ }^{[32]}$. The present data, based on a sample of Chinese adults, are consistent with published findings on diets of energy density and diet quality of a large representative sample of adults in the United States ${ }^{[1,27]}$ and France ${ }^{[10,33]}$. A study from China shows that vegetables and fruits had the lowest energy density, but their food prices were the highest per unit of energy ${ }^{[24]}$. The ability to adopt more healthful and, therefore, more costly diets can be viewed as behavior as an economic issue, which may have implications for some of the current strategies for health promotion.

The concept of nutrient density is critical to a better understanding of the relation between diet quality and its cost. Our finding that daily energy-adjusted diet cost was inversely associated with NRF9.2, MAR consistent with the results of several other studies. Drewnowski et al. found that nutrient density score were positively associated with diet cost per $100 g^{[34]}$. Meanwhile, 
from a nutritional qualitypoint of view, Drewnowski et al. also found that nutrient adequacy scores was positively associated with diet cost per $1000 \mathrm{kcal}^{[34]}$ and Matthieu et al. showed that for a given energy intake and energy density, each $10 \%$ increase in MAR led to a $13 \%$ increase in estimated diet costs per $10 \mathrm{MJ}^{[35]}$. In general, economic forces may hold the key to dietary change, given that the more nutrient-dense foods and higher-quality diets tended to be more expensive on a per calorie basis $^{[36]}$. Meanwhile, there are also some examples where changing food prices can improve dietary quality or improve clinical outcomes. Beydoun et al found that an annual rate of change in the monetary value of the diet may have a stronger impact on dietary quality among American urban adult women and above-poverty individuals ${ }^{[37]}$. Anne Magnus et al. found that the costeffectiveness of a $20 \%$ price discount on healthy food and beverages with and without consumer nutrition education led to a net loss of population health $-3695 \% \mathrm{Cl}(-47,-25)$ or $-21(-28,-15)$ disability-adjusted life years (DALYs) respectively in remote Australian ${ }^{[38]}$. Thus, for healthpromotion campaigns to be effective, it is essential that food prices are indeed a policy concern to ensure a nutritious food supply now and for future generations.

Arguably, not all healthier diets are necessarily associated with higher costs. It has been reported that healthy diets can be obtained at different cost levels. Mexican-Americans were found to consume higher-quality diets with lower costs than other populations ${ }^{[39]}$. And Zhou et al. found that it was not considered that the more expensive the food was $邓$ the higher the nutritive

value it had in each group of foods ${ }^{[24]}$.Because the more food is processed, the more nutrients are lost, and the higher the unit price is. These studies highlight the need to identify dietary patterns that are both healthful and affordable for Chinese adults.

The present study is the first to provide evidence for an inverse relationship between dietary quality (from the dimensions of nutrient density, energy density and, nutrient adequacy) and daily energy-adjusted diet costs among Chinese adults. However, there are important limitations. First, in the absence of food expenditure data, the model was based on the national website and retail food prices. In effect, the model estimated what each diet cost, as opposed to what the consumer paid for it. However, a similar method was used in previous observational studies ${ }^{[40]}$. Secondly, the modeling of diet cost was based on the strong assumption that most foods consumed, other than fast foods, were purchased at retail and prepared at home. The validity of the diet cost estimates for individuals who frequently consumed away-from-home foods and beverages would likely be below. It is worth noting that this limitation is common to epidemiologic studies on dietary exposures. Furthermore, the participants' food records were only collected 2 days by 24-h dietary recalls method. Thus, the data may not provide an accurate reflection of daily dietary behaviour and food group. Thus, findings may be limited in their generalizability. Finally, our data were cross-sectional, and therefore, possible causal pathways indicated by the mediation analyses cannot be confirmed. Despite these limitations, our estimates of daily energy-adjusted diet costs and diet quality were comparable to those obtained from other sources. More research on larger and more diverse populations will be needed to establish whether the trade-offs between cost and quality of the diet revealed our sample also exists in other groups.

\section{Conclusion}

The present results confirm past observations that a higher daily energy-adjusted cost diet tends to intake a high proportion of beneficial foods or nutrients recommended by the Chinese nutrition society. The most important result of our study was that daily energy-adjusted diet cost increased with higher adherence to the higher diet quality (NRF9.2, MAR, and ED). Furthermore, an increase in the energy-adjusted diet cost per day wasassociated with a positive change in the NRF9.2 and MAR, and with a negative in ED.The findings from our study indicate that to promote dietary quality, monetarycosts of foods or diets should be considered among northeast central Chinese adults.Otherwise, this effort will runthe risk of being in vain, particularly in lowincome groups.

\section{Declarations}

\section{Acknowledgements}

We thank the participants for their willingness to participate in this study. Our special thanks go to Yafei Sun and Xiumei Xu for their assistance with the collection and input of the data. 
All authors had full access to all of the data and take responsibility for the integrity of the data and the accuracy of the data analysis. Baihui Ma, Lijun Guo, Yongxia Kong acquired the data. Junya Zhai, Baihui Ma and Rui Liang analyzed, and interpreted the data. Junya Zhai, Baihui Ma, Saiqi Wang drafted the manuscript, which was critically revised for important intellectual content by all authors. Quanjun Lyu and Minghua Cong were responsible for the statistical analysis and revised the manuscript. Junya Zhai supervised the study and is a guarantor.

\section{Availability of data and materials}

The datasets used and/or analyzed during the current study are available from the corresponding author on reasonable request.

\section{Ethics approval and consent to participate}

The Committee on Human Subjects at The first affiliated hospital of Zhengzhou University approved the study design (Protocol 2020-KY-066). All subjects have signed a consent form to participate in the study.

\section{Consent for publication}

Not applicable.

\section{Competing interests}

The authors declare that they have no competing interests.

\section{References}

[1] Health effects of dietary risks in 195 countries, 1990-2017: A systematic analysis for the global burden of disease study 2017 [J]. Lancet, 2019,393(10184):1958-1972.

[2] Schwingshackl L, Bogensberger B, Hoffmann G. Diet quality as assessed by the healthy eating index, alternate healthy eating index, dietary approaches to stop hypertension score, and health outcomes: An updated systematic review and metaanalysis of cohort studies [J]. J Acad Nutr Diet, 2018,118(1):74-100 e111.

[3] Molendijk M, Molero P, Ortuño Sánchez-Pedreño F, et al. Diet quality and depression risk: A systematic review and doseresponse meta-analysis of prospective studies [J]. J Affect Disord, 2018,226(346-354.

[4]http://www.euro.who.int/_data/assets/pdf_file/0005/270716/Europe-nutrient-profile-model-2015-en.pdf?ua=1.

[5] Kalenkoski CM, Hamrick KS. How does time poverty affect behavior? A look at eating and physical activity [J]. Applied Economic Perspectives and Policy, 2013,35(1).

[6] Darmon N, Drewnowski A. Contribution of food prices and diet cost to socioeconomic disparities in diet quality and health: A systematic review and analysis [J]. Nutr Rev, 2015,73(10):643-660.

[7] Beydoun MA, Fanelli-Kuczmarski MT, Allen A, et al. Monetary value of diet is associated with dietary quality and nutrient adequacy among urban adults, differentially by sex, race and poverty status [J]. PLoS One, 2015,10(11):e0140905.

[8] Pondor I, Gan WY, Appannah G. Higher dietary cost is associated with higher diet quality: A cross-sectional study among selected malaysian adults [J]. Nutrients, 2017,9(9).

[9] Schröder H, Marrugat J, Covas MI. High monetary costs of dietary patterns associated with lower body mass index: A population-based study [J]. Int J Obes (Lond), 2006,30(10):1574-1579. 
[10] Darmon N, Briend A, Drewnowski A. Energy-dense diets are associated with lower diet costs: A community study of french adults [J]. Public Health Nutr, 2004,7(1):21-27.

[11] Monsivais P, Drewnowski A. Lower-energy-density diets are associated with higher monetary costs per kilocalorie and are consumed by women of higher socioeconomic status [J]. J Am Diet Assoc, 2009,109(5):814-822.

[12] Raynor HA, Kilanowski CK, Esterlis I, et al. A cost-analysis of adopting a healthful diet in a family-based obesity treatment program [J]. J Am Diet Assoc, 2002,102(5):645-656.

[13] Burney J, Haughton B. Efnep: A nutrition education program that demonstrates cost-benefit [J]. J Am Diet Assoc, 2002,102(1):39-45.

[14] Zhang X, Gong Y, Jia P, et al. Monetary diet cost is positively associated with diet quality and obesity: An analysis of school-aged children in southwest china [J]. J Public Health (Oxf), 2019,41(2):250-258.

[15] Bu T, Tang D, Liu Y, et al. Trends in dietary patterns and diet-related behaviors in china [J]. Am J Health Behav, 2021,45(2):371-383.

[16] Huang TT, Roberts SB, Howarth NC, et al. Effect of screening out implausible energy intake reports on relationships between diet and bmi [J]. Obes Res, 2005,13(7):1205-1217.

[17] YuexinYang. China food composition tables [M]. 2019.

[18] Nutrition CSo. Chinese dietary reference intakes (2013) [M]. Beijing,China: Science Press, 2014.

[19] Drewnowski A, Fulgoni VL, 3rd. Nutrient density: Principles and evaluation tools [J]. Am J Clin Nutr, 2014,99(5 Suppl):1223S-1228S.

[20] Madden JP, Goodman SJ, Guthrie HA. Validity of the 24-hr. Recall. Analysis of data obtained from elderly subjects [J]. Journal of the American Dietetic Association, 1976,68(2):143-147.

[21] Ledikwe JH, Blanck HM, Khan LK, et al. Dietary energy density determined by eight calculation methods in a nationally representative united states population [J]. J Nutr, 2005,135(2):273-278.

[22] Cox DN, Mela DJ. Determination of energy density of freely selected diets: Methodological issues and implications [J]. Int J Obes Relat Metab Disord, 2000,24(1):49-54.

[23] http://fgw.zhengzhou.gov.cn/search/index.jhtml.

[24] Zhenghua Zhou ZL, Chimei Pan, Bo Deng. The price of foods related to their nutritive value in urban area of nanchong [J]. Journal of North Sichuan Medical College, 2012,27(5):484-488.

[25] Venn D, Dixon J, Banwell C, et al. Social determinants of household food expenditure in australia: The role of education, income, geography and time [J]. Public Health Nutr, 2018,21(5):902-911.

[26] Society CN. Dietary guidelines for chinese residents(2016) [M]. Beijing: People's Medical Publishing House, 2016.

[27] Townsend MS, Aaron GJ, Monsivais P, et al. Less-energy-dense diets of low-income women in california are associated with higher energy-adjusted diet costs [J]. Am J Clin Nutr, 2009,89(4):1220-1226.

[28] Andrieu E, Darmon N, Drewnowski A. Low-cost diets: More energy, fewer nutrients [J]. Eur J Clin Nutr, 2006,60(3):434-436.

[29] Darmon N, Ferguson EL, Briend A. Impact of a cost constraint on nutritionally adequate food choices for french women: An analysis by linear programming [J]. J Nutr Educ Behav, 2006,38(2):82-90. 
[30] McLaughlin C, Tarasuk V, Kreiger N. An examination of at-home food preparation activity among low-income, foodinsecure women [J]. J Am Diet Assoc, 2003,103(11):1506-1512.

[31] Ledikwe JH, Blanck HM, Khan LK, et al. Low-energy-density diets are associated with high diet quality in adults in the united states [J]. J Am Diet Assoc, 2006,106(8):1172-1180.

[32] Drewnowski A, Specter SE. Poverty and obesity: The role of energy density and energy costs [J]. Am J Clin Nutr, 2004,79(1):6-16.

[33] Drewnowski A, Monsivais P, Maillot M, et al. Low-energy-density diets are associated with higher diet quality and higher diet costs in french adults [J]. J Am Diet Assoc, 2007,107(6):1028-1032.

[34] Drewnowski A, Maillot M, Darmon N. Testing nutrient profile models in relation to energy density and energy cost [J]. Eur J Clin Nutr, 2009,63(5):674-683.

[35] Maillot M, Darmon N, Vieux F, et al. Low energy density and high nutritional quality are each associated with higher diet costs in french adults [J]. Am J Clin Nutr, 2007,86(3):690-696.

[36] Drewnowski A. Nutrition economics: How to eat better for less [J]. J Nutr Sci Vitaminol (Tokyo), 2015,61 Suppl(S69-71.

[37] Beydoun MA, Fanelli-Kuczmarski MT, Poti J, et al. Longitudinal change in the diet's monetary value is associated with its change in quality and micronutrient adequacy among urban adults [J]. PLoS One, 2018,13(10):e0204141.

[38] Magnus A, Cobiac L, Brimblecombe J, et al. The cost-effectiveness of a $20 \%$ price discount on fruit, vegetables, diet drinks and water, trialled in remote australia to improve indigenous health [J]. PLoS One, 2018,13(9):e0204005.

[39] Monsivais P, Rehm CD, Drewnowski A. The dash diet and diet costs among ethnic and racial groups in the united states [J]. JAMA Intern Med, 2013,173(20):1922-1924.

[40] Rydén PJ, Hagfors L. Diet cost, diet quality and socio-economic position: How are they related and what contributes to differences in diet costs? [J]. Public Health Nutr, 2011,14(9):1680-1692.

\section{Tables}

Table 1 Mean estimated daily dietary cost and energy adjusted dietary cost by demographic and socio-economic strata among northeast central Chinese adults 


\begin{tabular}{|c|c|c|c|c|c|}
\hline & \multirow[b]{2}{*}{$\mathrm{n}$} & \multicolumn{2}{|c|}{$\begin{array}{l}\text { Daily diet cost } \\
(\mathrm{CNY} / \mathrm{d})^{1}\end{array}$} & \multicolumn{2}{|c|}{$\begin{array}{l}\text { Daily Energy-adjusted diet cost } \\
(\mathrm{CNY} / 2000 \mathrm{kcal})^{2}\end{array}$} \\
\hline & & Mean & SD & Mean & SD \\
\hline Total & 680 & 14.05 & 10.08 & 19.14 & 12.75 \\
\hline \multicolumn{6}{|l|}{ Gender } \\
\hline Men & 422 & 14.51 & 11.23 & 18.43 & 13.54 \\
\hline Women & 258 & 13.32 & 7.81 & 20.30 & 11.26 \\
\hline \multicolumn{6}{|l|}{ Age } \\
\hline$<50$ & 102 & 14.55 & 8.19 & 20.54 & 10.08 \\
\hline $50-65$ & 422 & 14.00 & 8.59 & 18.99 & 13.18 \\
\hline$>65$ & 156 & 13.88 & 14.18 & 18.63 & 13.13 \\
\hline \multicolumn{6}{|l|}{ Family income level * } \\
\hline$<¥ 2000$ /month/person & 125 & 12.12 & 7.53 & 16.89 & 9.64 \\
\hline$¥ 2000 \sim ¥ 5000 /$ month/person & 387 & 13.60 & 8.13 & 18.78 & 13.12 \\
\hline >¥5000/month/person & 168 & 16.54 & 14.47 & 21.66 & 13.55 \\
\hline \multicolumn{6}{|l|}{ Educational level } \\
\hline$<6$ years & 87 & 12.52 & 9.26 & 17.68 & 11.29 \\
\hline $6 \sim 12$ years & 437 & 14.07 & 10.67 & 18.92 & 13.52 \\
\hline$>12$ years & 156 & 14.87 & 8.69 & 20.58 & 11.11 \\
\hline \multicolumn{6}{|l|}{ Occupation* } \\
\hline Manual & 110 & 11.66 & 7.58 & 17.03 & 9.51 \\
\hline Professional & 85 & 13.62 & 8.74 & 18.59 & 10.82 \\
\hline Retired & 335 & 14.67 & 8.90 & 19.35 & 11.45 \\
\hline Others & 150 & 14.67 & 13.97 & 20.54 & 17.58 \\
\hline \multicolumn{6}{|l|}{ Marriage } \\
\hline Yes & 621 & 14.07 & 10.21 & 19.23 & 13.01 \\
\hline Others & 59 & 13.89 & 8.69 & 18.21 & 9.55 \\
\hline
\end{tabular}

1. Values were presented as mean and standard deviation (SD).

2. Values were presented as mean and SD. Energy-adjusted diet cost was calculated by dividing the estimated daily diet costs (CNY/day) by the energy intake per day (kcal/day) and multiplying 2000.

3. The general characteristics of the distribution of daily diet cost and energy-adjusted diet cost were tested by t-test or analysis of variance test, and if there was a difference marked star. $*$ indicates that $p$-value $<0.05$.

Table 2 Means of food group intake within each quartile of daily energy-adjusted diet cost ${ }^{1}$ 


\begin{tabular}{|llllll|}
\hline Food group & \multicolumn{2}{l}{ Daily energy-adjusted diet cost ${ }^{2}$} & & \multirow{2}{*}{$P^{3}$} \\
\cline { 2 - 5 } & Q1 & Q2 & Q3 & Q4 & \\
\hline $\mathrm{n}$ & 175 & 176 & 176 & 175 & $<0.0001$ \\
\hline Energy-adjusted diet cost & $8.81 \pm 1.20$ & $13.81 \pm 1.20$ & $19.22 \pm 2.05$ & $34.69 \pm 16.26$ & $<0.0001$ \\
\hline Grains & $465.02 \pm 176.29$ & $466.06 \pm 192.17$ & $398.27 \pm 174.96$ & $321.44 \pm 166.45$ & $<$ \\
\hline Vegetables & $157.35 \pm 104.89$ & $172.76 \pm 133.51$ & $154.71 \pm 124.94$ & $159.24 \pm 146.29$ & 0.6 \\
\hline Fruits & $44.01 \pm 84.55$ & $140.63 \pm 165.23$ & $271.92 \pm 277.20$ & $342.84 \pm 400.42$ & $<0.0001$ \\
\hline Milk and milk products & $8.51 \pm 36.79$ & $43.54 \pm 111.07$ & $50.34 \pm 109.35$ & $45.41 \pm 114.62$ & $<0.0001$ \\
\hline Beans & $16.26 \pm 38.05$ & $18.99 \pm 55.36$ & $27.15 \pm 71.87$ & $19.74 \pm 88.63$ & $<0.0001$ \\
\hline nuts & $3.48 \pm 8.15$ & $11.88 \pm 36.83$ & $14.48 \pm 47.53$ & $13.67 \pm 42.50$ & 0.03 \\
\hline Meat, poultry & $23.41 \pm 45.09$ & $37.57 \pm 54.94$ & $71.23 \pm 111.04$ & $114.67 \pm 163.62$ & $<0.0001$ \\
\hline Fish & $1.54 \pm 9.85$ & $4.20 \pm 18.55$ & $8.54 \pm 33.94$ & $28.46 \pm 65.26$ & $<0.0001$ \\
\hline Egg & $43.31 \pm 46.15$ & $50.63 \pm 53.80$ & $45.23 \pm 43.53$ & $40.95 \pm 47.73$ & 0.3 \\
\hline oil & $13.74 \pm 9.78$ & $16.97 \pm 14.60$ & $16.12 \pm 14.86$ & $15.85 \pm 15.20$ & 0.2 \\
\hline Others ${ }^{4}$ & $11.25 \pm 25.13$ & $21.93 \pm 63.66$ & $39.26 \pm 94.80$ & $80.89 \pm 256.97$ & $<0.0001$ \\
\hline
\end{tabular}

1. Values were presented as mean $\pm S D$.

2. Q1, 1st quartile; Q2, 2nd quartile; Q3, 3rd quartile; Q4, 4th quartile.

3. The differences of food groups intake among quartiles of energy-adjusted diet cost were tested by analysis of variance test.

4. Snacks includes cookies, fast food, sugar preserved fruits and so on.

Table 3 Means of nutrients intake within each quartile of daily energy-adjusted diet cost ${ }^{4}$ 


\begin{tabular}{|c|c|c|c|c|c|}
\hline \multirow{2}{*}{$\begin{array}{l}\text { Energy } \\
\text { and nutrients }\end{array}$} & \multicolumn{4}{|c|}{ Daily energy-adjusted diet cost ${ }^{1}$} & \multirow[t]{2}{*}{$P \rrbracket^{3}$} \\
\hline & Q1 & Q2 & Q3 & Q4 & \\
\hline $\mathrm{n}$ & 170 & 169 & 171 & 170 & \\
\hline Energy (kcal) & $1474 \pm 427$ & $1605 \pm 448$ & $1587 \pm 508$ & $1449 \pm 427$ & 0.03 \\
\hline Protein (g) & $47.18 \pm 18.14$ & $53.05 \pm 17.76$ & $53.03 \pm 18.24$ & $55.77 \pm 22.34$ & 0.001 \\
\hline Fat (g) & $31.06 \pm 13.53$ & $42.15 \pm 21.02$ & $44.28 \pm 21.17$ & $40.10 \pm 19.38$ & $<0.0001$ \\
\hline Carbohydrate (g) & $253 \pm 78$ & $255 \pm 74$ & $246 \pm 91$ & $218 \pm 76$ & $<0.000$ \\
\hline Fiber (g) & $11.74 \pm 6.87$ & $13.42 \pm 5.84$ & $12.99 \pm 5.89$ & $13.02 \pm 8.96$ & 0.2 \\
\hline Vitamin $\mathrm{B}_{1}(\mathrm{mg})$ & $0.71 \pm 0.31$ & $0.76 \pm 0.32$ & $0.80 \pm 0.37$ & $0.78 \pm 0.38$ & 0.1 \\
\hline Vitamin $B_{2}(\mathrm{mg})$ & $0.53 \pm 0.23$ & $0.66 \pm 0.28$ & $0.72 \pm 0.30$ & $0.79 \pm 0.39$ & $<0.0001$ \\
\hline Niacin (mg) & $7.82 \pm 4.61$ & $9.23 \pm 4.26$ & $10.58 \pm 4.57$ & $11.06 \pm 5.86$ & $<0.0001$ \\
\hline Vitamin A ( $\mu \mathrm{gRAE})$ & $347 \pm 372$ & $403 \pm 340$ & $451 \pm 520$ & $568 \pm 731$ & 0.001 \\
\hline Vitamin C (mg) & $46.35 \pm 36.12$ & $62.88 \pm 51.29$ & $68.15 \pm 46.56$ & $83.58 \pm 63.18$ & $<0.0001$ \\
\hline Vitamin E (mga-TE) & $16.08 \pm 7.79$ & $18.85 \pm 8.60$ & $20.64 \pm 11.82$ & $19.64 \pm 14.68$ & 0.002 \\
\hline Potassium(mg) & $1168 \pm 654$ & $1420 \pm 469$ & $1573 \pm 587$ & $1660 \pm 685$ & $<0.0001$ \\
\hline Calcium(mg) & $228 \pm 147$ & $298 \pm 158$ & $309 \pm 159$ & $342 \pm 214$ & $<0.0001$ \\
\hline Iron (mg) & $14.05 \pm 6.49$ & $15.02 \pm 5.25$ & $15.40 \pm 6.23$ & $17.42 \pm 28.04$ & 0.2 \\
\hline Magnesium (mg) & $224 \pm 95$ & $237 \pm 75$ & $234 \pm 90$ & $248 \pm 124$ & 0.2 \\
\hline Phosphorous (mg) & $750 \pm 236$ & $806 \pm 251$ & $785 \pm 259$ & $807 \pm 301$ & 0.2 \\
\hline Zinc (mg) & $6.93 \pm 2.63$ & $7.67 \pm 2.51$ & $7.78 \pm 2.65$ & $8.57 \pm 4.06$ & $<0.0001$ \\
\hline Selenium ( $\mu \mathrm{g})$ & $40.27 \pm 17.90$ & $40.60 \pm 18.92$ & $38.57 \pm 18.76$ & $43.93 \pm 25.59$ & 0.1 \\
\hline MAR & $0.53 \pm 0.13$ & $0.60 \pm 0.13$ & $0.63 \pm 0.13$ & $0.64 \pm 0.14$ & $<0.0001$ \\
\hline
\end{tabular}

1. Values were presented as mean $\pm S D$.

2. Q1, 1st quartile; Q2, 2nd quartile; Q3, 3rd quartile; Q4, 4th quartile.

3. The differences of nutrients intake among quartiles of energy-adjusted diet cost were tested by analysis of variance test.

Table 4 Daily energy-adjusted diet cost (CNY/2000kcal) of foodsaccording to the adherence to diet quality index (NRF9.2, MAR, ED) 


\begin{tabular}{|c|c|c|c|c|c|c|}
\hline & \multicolumn{4}{|l|}{ NRF9.2 Index ${ }^{2}$} & \multirow[t]{2}{*}{$\beta$} & \multirow{2}{*}{$\begin{array}{l}\text { Pfor- } \\
\text { trend }^{\beta}\end{array}$} \\
\hline & Q1 & Q2 & Q3 & Q4 & & \\
\hline \multicolumn{7}{|c|}{ Daily energy-adjusted diet cost } \\
\hline $\begin{array}{l}\text { Unadjusted } \\
\text { model }\end{array}$ & $\begin{array}{l}\text { 16.42(14.83, } \\
18.19)\end{array}$ & $\begin{array}{l}17.50(15.81 \\
19.19)\end{array}$ & $\begin{array}{l}17.60(15.91 \\
19.28)\end{array}$ & $\begin{array}{l}\text { 25.31(23.66, } \\
26.96)\end{array}$ & 0.296 & $<0.0001$ \\
\hline \multirow{3}{*}{$\begin{array}{l}\text { Adjusted } \\
\text { model }^{4}\end{array}$} & $16.42(14.76,18.09)$ & $17.44(15.75,19.12)$ & $17.74(16.05,19.43)$ & $25.34(23.67,27.00)$ & 0.284 & $<0.0001$ \\
\hline & MAR & & & & \multirow[t]{2}{*}{$\beta$} & \multirow{2}{*}{$\begin{array}{l}\text { Pfor- } \\
\text { trend }^{\beta}\end{array}$} \\
\hline & Q1 & Q2 & Q3 & Q4 & & \\
\hline \multicolumn{7}{|c|}{ Daily energy-adjusted diet cost } \\
\hline $\begin{array}{l}\text { Unadjusted } \\
\text { model }\end{array}$ & $\begin{array}{l}15.50(13.80 \\
17.21)\end{array}$ & $\begin{array}{l}\text { 18.52(16.82, } \\
20.21)\end{array}$ & $\begin{array}{l}19.64(17.94 \\
21.34)\end{array}$ & $\begin{array}{l}22.33(20.63, \\
24.04)\end{array}$ & 20.86 & $<0.0001$ \\
\hline \multirow[t]{3}{*}{$\begin{array}{l}\text { Adjusted } \\
\text { model }^{4}\end{array}$} & $\begin{array}{l}\text { 12.59(10.57, } \\
14.61)\end{array}$ & $\begin{array}{l}\text { 17.97(16.21, } \\
19.72)\end{array}$ & $\begin{array}{l}20.60(18.67 \\
22.33)\end{array}$ & $\begin{array}{l}25.76(23.75 \\
27.76)\end{array}$ & 44.77 & $<0.0001$ \\
\hline & ED(all food) & & & & \multirow[t]{2}{*}{$\beta$} & \multirow{2}{*}{$\begin{array}{l}\text { Pfor- } \\
\text { trend }^{3}\end{array}$} \\
\hline & Q1 & Q2 & Q3 & Q4 & & \\
\hline \multicolumn{7}{|c|}{ Daily energy-adjusted diet cost } \\
\hline $\begin{array}{l}\text { Unadjusted } \\
\text { model }\end{array}$ & $\begin{array}{l}28.83(27.11 \\
30.54)\end{array}$ & $\begin{array}{l}\text { 17.92(16.21, } \\
19.63)\end{array}$ & $\begin{array}{l}\text { 16.41(14.70, } \\
18.12)\end{array}$ & $\begin{array}{l}\text { 13.42(11.70, } \\
15.12)\end{array}$ & -13.14 & $<0.0001$ \\
\hline $\begin{array}{l}\text { Adjusted } \\
\text { model }^{4}\end{array}$ & $\begin{array}{l}28.49(26.83 \\
30.15)\end{array}$ & $\begin{array}{l}\text { 18.59(17.01, } \\
20.16)\end{array}$ & $\begin{array}{l}\text { 16.74(15.61, } \\
18.32)\end{array}$ & $\begin{array}{l}\text { 14.15(12.53, } \\
15.77)\end{array}$ & -11.51 & $<0.0001$ \\
\hline
\end{tabular}

1. Values are model-adjusted least-squares means; $95 \% \mathrm{Cls}$ in parentheses.

2. Calculated by dividing the estimated daily diet costs (CNY/day) by the energy intake per day (kcal/day) and multiplying 2000.

3. Linear trends (P for-trend) were obtained with ordinal median Daily energy-adjusted diet cost (CNY/2000kcal) for each quartile as continuous variables.

4. Adjusted for age (years), gender (male or female), family income level (<¥2000/month/person, ¥2000$¥ 5000 /$ month/person, $\geq ¥ 5000 /$ month/person) and food intake (kcal).

Table 5 Multiple linear regression least-squares means and 95\% confidence interval for the association of daily energyadjusted diet costs with diet quality $(n=702)^{1}$ 


\begin{tabular}{|c|c|c|c|c|c|c|}
\hline & \multicolumn{4}{|c|}{ Daily energy-adjusted diet cost ${ }^{2}$} & \multirow[t]{2}{*}{$\beta$} & \multirow[b]{2}{*}{$\begin{array}{l}\text { Pfor- } \\
\text { trend }^{\beta}\end{array}$} \\
\hline & Q1 & Q2 & Q3 & Q4 & & \\
\hline$n$ & 170 & 169 & 171 & 170 & & \\
\hline \multicolumn{7}{|l|}{ NRF9.2 Index } \\
\hline $\begin{array}{l}\text { Unadjusted } \\
\text { model }\end{array}$ & $\begin{array}{l}37.04(34.82 \\
39.26)\end{array}$ & $\begin{array}{l}37.85(35.67 \\
40.02)\end{array}$ & $\begin{array}{l}40.52(38.36 \\
42.68)\end{array}$ & $\begin{array}{l}47.60(45.43 \\
49.76)\end{array}$ & 0.504 & $<0.0001$ \\
\hline $\begin{array}{l}\text { Adjusted } \\
\text { model }^{4}\end{array}$ & $\begin{array}{l}36.93(34.49 \\
39.36)\end{array}$ & $\begin{array}{l}37.94(35.65 \\
40.23)\end{array}$ & $\begin{array}{l}40.26(38.03 \\
42.48)\end{array}$ & $\begin{array}{l}47.20(44.91 \\
49.49)\end{array}$ & 0.494 & $<0.0001$ \\
\hline \multicolumn{7}{|l|}{ MAR } \\
\hline $\begin{array}{l}\text { Unadjusted } \\
\text { model }\end{array}$ & $0.53(0.51,0.55)$ & $0.60(0.59,0.61)$ & $0.63(0.51,0.65)$ & $0.64(0.62,0.66)$ & 0.003 & $<0.0001$ \\
\hline $\begin{array}{l}\text { Adjusted } \\
\text { model }^{4}\end{array}$ & $0.56(0.54,0.57)$ & $0.59(0.57,0.60)$ & $0.61(0.60,0.63)$ & $0.66(0.650 .68)$ & 0.003 & $<0.0001$ \\
\hline \multicolumn{7}{|l|}{ ED(all food) } \\
\hline $\begin{array}{l}\text { Unadjusted } \\
\text { model }\end{array}$ & $1.92(1.86,1.98)$ & $1.62(1.56,1.68)$ & $1.47(1.41,1.54)$ & $1.39(1.33,1.46)$ & -0.017 & $<0.0001$ \\
\hline $\begin{array}{l}\text { Adjusted } \\
\text { model }^{4}\end{array}$ & $1.91(1.85,1.98)$ & $1.61(1.55,1.67)$ & $1.49(1.43,1.55)$ & $1.41(1.34,1.45)$ & -0.018 & $<0.0001$ \\
\hline
\end{tabular}

1. Values are model-adjusted least-squares means; $95 \% \mathrm{Cls}$ in parentheses.

2. Calculated by dividing the estimated daily diet costs (CNY/day) by the energy intake per day (kcal/day) and multiplying 2000.

3. Linear trends (P for-trend) were obtained with ordinal median diet quality (NRF9.2 INDEX, MAR, ED) for each quartile as continuous variables.

4. Adjusted for age (years), gender (male or female), family income level (<¥2000/month/person, ¥2000$¥ 5000 /$ month/person, $\geq ¥ 5000 /$ month/person) and food intake (kcal). 